\title{
Response to: Comparison of laser Doppler imaging, fingertip lacticemy test, and nailfold capillaroscopy for assessment of digital microcirculation in systemic sclerosis - authors' reply
}

\author{
Marcelo JU Correa, Luis EC Andrade and Cristiane Kayser* \\ See related letter by Sulli et al., http://arthritis-research.com/content/13/1/301, and related research by Correa et al., \\ http://arthritis-research.com/content/12/4/R157
}

We thank Sulli and colleagues [1] for their interest in our article entitled 'Comparison of laser Doppler imaging, fingertip lacticemy test, and nailfold capillaroscopy for assessment of digital microcirculation in systemic sclerosis' [2], which was published in a recent issue of Arthritis Research \& Therapy. Sulli and colleagues commented on our results regarding the lack of correlation between the laser Doppler imaging (LDI) technique and nailfold capillaroscopy (NFC) and raised interesting questions.

We totally agree with the comment that NFC is a powerful tool for the assessment of microvascular damage in systemic sclerosis (SSc). Recently, we showed a positive correlation between NFC abnormalities and the extent of cutaneous and visceral involvement in SSc patients, confirming that NFC is a relevant approach not only for diagnosis but also for the evaluation of the extension and severity of SSc [3]. However, NFC evaluates only the morphological aspect of SSc vasculopathy, and complementary tools are used, with different results, in many studies for the evaluation of functional aspects of peripheral vascular disease [4].

Sulli and colleagues mentioned three interesting, recently published papers [5-7] with results different from those of our paper. However, different methods for the evaluation of blood perfusion were used in each of them, and it is difficult to compare results obtained with different techniques. Cutolo and colleagues [5] assessed fingertip blood perfusion by laser Doppler flowmetry, and Mugii and colleagues [6] evaluated red blood cell velocity by means of videocapillaroscopy. We emphasize

${ }^{*}$ Correspondence: criskayser@terra.com.br

Rheumatology Division, Department of Medicine, Universidade Federal de São Paulo, Rua Botucatu $7403^{\circ}$ andar, São Paulo, 04023-062, Brazil that only Rosato and colleagues [7], who were considered in our original paper, evaluated blood perfusion by means of LDI. Moreover, the mechanisms involved in SSc vasculopathy are complex, and controversial findings are not surprising. The LDI method used in our original study is considered the most promising tool for the study of microvascular blood flow. In our study, LDI showed lower digital blood flow in SSc patients when compared with healthy controls and correlated negatively with fingertip lacticemy, allowing objective measurement of blood perfusion. It is also relevant to point out that Murray and colleagues [4] showed only a weak correlation between intercapillary distance measured by NFC and the blood flow also measured by LDI. As in our study, the authors could not find any other correlation between other NFC parameters and LDI.

Therefore, it is appropriate to consider that different techniques such as LDI (dynamic changes) and NFC (morphology changes) complement one another. Of course, further studies with a larger sample of patients assessed by the same technique are required to evaluate possible discrepancies between different studies.

\section{Abbreviations}

LDI, laser Doppler imaging; NFC, nailfold capillaroscopy; SSc, systemic sclerosis.

\section{Competing interests}

The authors declare that they have no competing interests.

\section{Acknowledgments}

Our study was supported by the State of São Paulo Research Foundation (FAPESP grant 06/59073-3) and partially by the Brazilian Society of Rheumatology Research Agency.

\section{Published: 24 January 2011}

\section{References}

1. Sulli A, Smith V, Cutolo M: Response to: Comparison of laser Doppler imaging, fingertip lacticemy test, and nailfold capillaroscopy for assessment of digital microcirculation in systemic sclerosis. Arthritis Res Ther 2010, 13:301. 
2. Correa JUC, Andrade LEC, Kayser C: Comparison of laser Doppler imaging, fingertip lacticemy test, and nailfold capillaroscopy for assessment of digital microcirculation in systemic sclerosis. Arthritis Res Ther 2010, 12:R157.

3. Sato LT, Kayser C, Andrade LEC: Nailfold capillaroscopy abnormalities correlate with cutaneous and visceral involvement in systemic sclerosis patients. Acta Reumatol Port 2009, 34:219-227.

4. Murray AK, Moore TL, Manning JB, Taylor C, Griffiths CE, Herrick AL: Noninvasive imaging techniques in the assessment of scleroderma spectrum disorders. Arthritis Rheum 2009, 61:1103-1111.

5. Cutolo M, Ferrone C, Pizzorni C, Soldano S, Seriolo B, Sulli A: Peripheral blood perfusion correlates with microvascular abnormalities in systemic sclerosis: a laser-Doppler and nailfold videocapillaroscopy study. J Rheumatol 2010, 37:1174-1180.

6. Mugii N, Hasegawa M, Hamaguchi Y, Tanaka C, Kaji K, Komura K,
Ueda-Hayakawa I, Horie S, Ikuta M, Tachino K, Ogawa F, Sato S, Fujimoto M, Takehara K: Reduced red blood cell velocity in nail-fold capillaries as a sensitive and specific indicator of microcirculation injury in systemic sclerosis. Rheumatology 2009, 48:696-703.

7. Rosato E, Borghese F, Pisarri S, Salsano F: Laser Doppler perfusion imaging is useful in the study of Raynaud's phenomenon and improves the capillaroscopic diagnosis. J Rheumato/ 2009, 36:2257-2263.

doi:10.1186/ar3200

Cite this article as: Correa MJU, et al:: Response to: Comparison of laser Doppler imaging, fingertip lacticemy test, and nailfold capillaroscopy for assessment of digital microcirculation in systemic sclerosis - authors' reply. Arthritis Research \& Therapy 2011, 13:302. 